\title{
Follicular Thyroid Carcinoma in a Country of Endemic Iodine Deficiency (1994-2013)
}

\author{
Edmund Muonir Der (iD ${ }^{1,2}$ \\ ${ }^{1}$ Department of Pathology, Korle-Bu Teaching Hospital, P.O. Box 77, Korle-Bu, Accra, Ghana \\ ${ }^{2}$ Department of Pathology, University for Development Studies, P.O. Box 1883, Tamale, Ghana \\ Correspondence should be addressed to Edmund Muonir Der; maadelle@yahoo.com
}

Received 26 September 2017; Revised 16 January 2018; Accepted 30 January 2018; Published 25 February 2018

Academic Editor: Malcolm H. Wheeler

Copyright (c) 2018 Edmund Muonir Der. This is an open access article distributed under the Creative Commons Attribution License, which permits unrestricted use, distribution, and reproduction in any medium, provided the original work is properly cited.

\begin{abstract}
Background. Follicular thyroid cancer (FTC) has historically been linked to iodine deficiency. Although Ghana is among the iodine deficient regions of the world, the proportions, trends, and the clinical features of FTCs have not been studied as a single disease entity. The aim of this study was to determine the relative frequencies, trends, and the clinicopathological characteristics of FTCs among all thyroid malignancies in our institution. Materials and Methods. This was a retrospective study from January 1994 to December 2013. Data were analysed using SPSS software version 23 (Chicago) and Graph pad prism version 5.00. Results. Follicular thyroid cancer was the second thyroid malignancy $(35.0 \%)$ and showed a gradual rise in relative proportions over the period. The male-female ratio was 1:1.5. The mean ages were 46.9 ( $\mathrm{SD} \pm 17.3)$ for males and $46.4(\mathrm{SD} \pm 13.3)$ years for females. Enlarged palpable anterior neck swelling was the commonest symptom in males $(86.7 \%)$ and females $(91.3 \%)(P=0.730)$. Hurthle cell carcinoma was the commonest variant of FTC, with $26.7 \%$ males and $10.6 \%$ females $(P=0.116)$. Distant spread was found in $23.3 \%$ of males compared to $19.1 \%$ of females $(P=0.633)$. The common sites of distant spread were bones $(57.2 \%)$ in males and cervical lymph nodes $(44.4 \%)$ in females $(P=0.106)$. Conclusion. Follicular thyroid cancer was the second common thyroid malignancy $(35.0 \%)$ with a gradual rise in trend over the study period and male-female ratio of $1.5: 1$. Large anterior neck swelling was the commonest clinical presentation of FTC.
\end{abstract}

\section{Introduction}

Follicular thyroid carcinoma (FTC) is a malignant epithelial tumour showing follicular cell differentiation and lacking the diagnostic nuclear features of papillary thyroid carcinoma (PTC) [1]. The incidence of FTCs varies across the globe reflecting the population studied, the environmental factors, the method of study, and the iodine status of the area [2]. Studies in Ghana [3, 4], some parts of Africa [5, 6], and beyond $[7,8]$ have found FTC as the second common type of differentiated carcinomas of the thyroid gland. However, others based on the low levels of iodine in certain geographical location $[9,10]$ found it to be the commonest differentiated carcinoma of the thyroid gland [11-13]. Follicular carcinoma usually presents as a single palpable neck mass. Incidence is $13-17 \%$ of all thyroid carcinomas [14]. It is common in middle and older age groups; the average age at diagnosis is 50 years. It affects females more commonly than males
[14-19]. Follicular thyroid cancer has historically been linked to iodine deficiency. The proportions, trend, and the clinical features of FTCs in Ghana, an iodine deficient country [2022], have not been studied as a single entity. The aim of this was to determine the relative frequencies, trends, and the clinicopathological characteristics of FTC among thyroid malignancies diagnosed (1994-2013) in our institution.

\section{Materials and Methods}

2.1. Study Design. This was a retrospective review from January 1994 to December 2013.

2.2. Study Site. The study was conducted in the Department of Pathology, Korle-Bu Teaching Hospital (KBTH), the largest referral hospital in Ghana. This department receives cases from the Korle- $\mathrm{Bu}$ teaching hospital, hospitals within the Accra Metropolis, and the surrounding towns and Districts. 
2.3. Data Collection and Analysis. All the histology request forms, the histology reports, and the corresponding histology slides of all thyroid malignancies diagnosed in our institution from January 1994 to December 2013 were reviewed. Data were collected on the demographic features and the histopathological characteristics of TCs diagnosed during the period of review. Data were entered into a statistical data base and analysed using SPSS software version 23.0 (Chicago) and Graph pad prism version 5.00 (https://www.graphpad.com for Windom).

The relative proportions of thyroid malignancies over the period of study were calculated.

The annual trend of follicular thyroid cancers (FTCs) over the period 1994-2013 was determined.

Descriptive statistics were computed for the ages (mean, standard deviation) of all patients included in the study.

The clinicopathological characteristics of follicular thyroid cancer including the types of surgical specimens were described. Comparisons were made between females and males using Fischer's exact test.

The histological subtypes FTC and their proportions were determined.

The results were presented in frequency tables and a histogram.

2.4. Availability of Data. The data used to prepared this manuscript will be made available on demand.

\section{Inclusion Criteria}

All histologically confirmed thyroid malignancies were included.

\section{Exclusion Criteria}

Poorly fixed specimens and cases with incomplete records were excluded (a total of 3). Reasons for exclusion are as follows: one case was submitted in fragments, making it difficult to access capsular invasion, one had only the patient's name on an $X$-ray request form, and the last one was poorly fixed with loss of structural details.

\section{Results}

5.1. Annual Distribution of Follicular Thyroid Carcinomas (1994-2013). Over the period of study, a total of 220 thyroid malignancies were diagnosed, of which 77 (35.0\%) were follicular thyroid cancers (FTCs), second to papillary thyroid carcinoma $116(52.7 \%)$. The others were medullary 22 (10.0\%) and anaplastic 5 (2.3\%). Over the period, there was a gradual rise in the numbers of FTCs diagnosed in our institution, Figure 1.

5.2. Age Characteristics of Patients Diagnosed with FTC. The ages of patients diagnosed with FTC range from 10 to 77 years with mean age of 46.7 years $(\mathrm{SD}=15.7)$ and a modal age group of $50-59$ years $22(28.6 \%)$, Figure 2.

There were $47(61.0 \%)$ and $30(39.0 \%)$, with a female to male ratio of $1.5: 1$. The ages of female with FTCs ranged from 10 to 77 with a mean age of $46.9(\mathrm{SD}=17.3)$ and a modal age

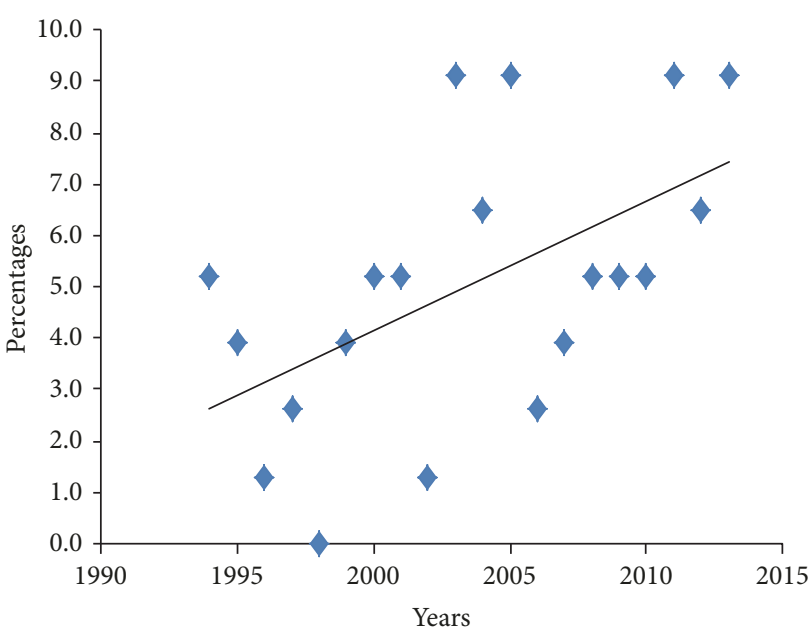

Figure 1: Annual Trend in FTC for the period 1994-2013.

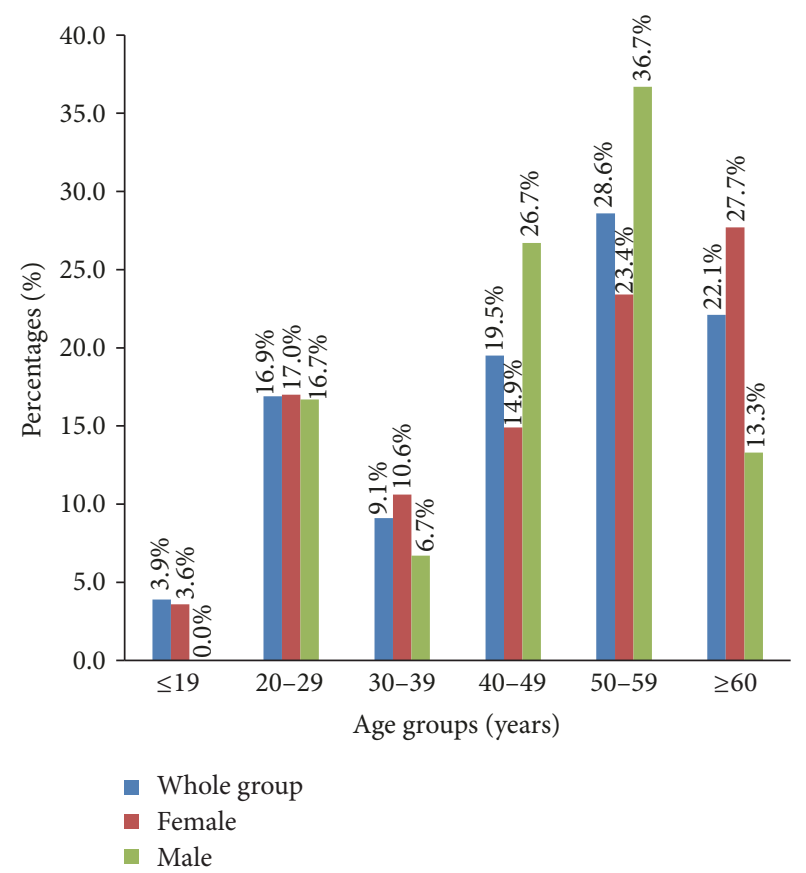

FIgURE 2: Age characteristics of patients diagnosed with thyroid cancers.

group being women aged 60 years and above (27.7\%), Figure 2 and Table 1 . The ages of the males ranged from 21 to 66 with a mean age of 46.4 years $(S D=13.3)$ and a modal age group of 50-59 years (36.7\%), Figure 2 and Table 1.

5.3. Clinical Presentation, Duration at Presentation, and Type of Surgical Specimens. The commonest symptom of TCs in both females $(91.3 \%)$ and males $(86.7 \%)$ was anterior neck swelling $(P$ value $=0.730)$. The duration of symptoms at presentation was available for 31 cases of which more than half $(52.7 \%)$ presented at 4 or more years followed by those who presented within one year of noticing the swelling (25.8\%). A total of 22 male cases had stated duration at presentation of which many $(31.8 \%)$ presented at 4 or more years, with $27.3 \%$ presenting within 3 years of onset of the disease, Table 1. 
TABLE 1: Demographic characteristics and the clinical presentation of FCTs in females and males.

\begin{tabular}{|c|c|c|c|}
\hline & Female $(n / \%)$ & Male $(n / \%)$ & $P$ value \\
\hline \multicolumn{4}{|l|}{ Age group (years) } \\
\hline$\leq 19$ & $3(6.4)$ & $0(0.0)$ & 0.277 \\
\hline $20-29$ & $8(17.0)$ & $5(16.7)$ & 1.000 \\
\hline $30-39$ & $5(10.6)$ & $2(6.7)$ & 0.699 \\
\hline $40-49$ & $7(14.9)$ & $8(26.7)$ & 0.245 \\
\hline $50-59$ & $11(23.4)$ & $11(36.7)$ & 0.301 \\
\hline$\geq 60$ & $13(27.7)$ & $4(13.3)$ & 0.168 \\
\hline \multicolumn{4}{|l|}{ Clinical presentation } \\
\hline Anterior neck swelling & $42(89.4)$ & $26(86.7)$ & 0.730 \\
\hline Pathological fracture & $0(0.0)$ & $2(6.7)$ & 0.149 \\
\hline Bone pain & $2(4.3)$ & $1(3.3)$ & 1.000 \\
\hline Soft tissue swelling & $3(6.3)$ & $1(3.3)$ & 1.000 \\
\hline \multicolumn{4}{|c|}{ Duration of symptoms at presentation (years) } \\
\hline 1 & $8(25.8)$ & $5(22.7)$ & 1.000 \\
\hline 2 & $2(6.5)$ & $4(18.2)$ & 0.201 \\
\hline 3 & $4(12.9)$ & $6(27.3)$ & 0.175 \\
\hline$\geq 4$ & $17(52.7)$ & $7(31.8)$ & 0.315 \\
\hline \multicolumn{4}{|l|}{ Surgical specimens } \\
\hline Total thyroidectomy & $22(46.8)$ & $14(46.7)$ & 1.000 \\
\hline Near total thyroidectomy & $5(10.6)$ & $4(13.3)$ & 0.730 \\
\hline Lobectomy & $12(25.6)$ & $4(13.3)$ & 0.256 \\
\hline Biopsy & $8(17.0)$ & $7(23.3)$ & 0.562 \\
\hline Neck dissection & $0(0.0)$ & $1(1.3)$ & 0.390 \\
\hline
\end{tabular}

In both females (46.8\%) and males (46.7\%), FTCs were commonly diagnosed in total thyroidectomy specimens, $(P$ value $=1.000$ ), Table 1 .

5.4. Histological Subtypes of FTCs. The great majority, 73 (94.8\%), of the FTCs were invasive, with only 3 (3.9\%) minimally invasive counterparts, Table 2. Conventional FTC was the commonest type in both groups [females $(80.9 \%)$, males $(60.0 \%)](P$ value $=0.066)$. Similarly, Hurthle cell carcinoma was the commonest variant of FTCs in this study, accounting for $10.6 \%$ in females and $26.7 \%$ in males ( $P$ value $=0.116)$, Table 2 .

5.5. Distant Spread at the Time of Histological Diagnosis. A total of $9(19.1 \%)$ of the female have their cancer spread outside the thyroid gland at diagnosis, mostly involving cervical lymph nodes $4(44.4 \%)$, $(P$ value $=0.633)$. For the males, 7 (23.3\%) had distant spread at diagnosis, commonly bony involvements $4(57.2 \%)(P$ value $=0.106)$, Table 2 .

\section{Discussion}

During the period under review, follicular thyroid cancer (FTC) was the second thyroid cancer, accounting for $35.0 \%$ of all the thyroid malignancies. This is in keeping with previous studies in Ghana [3, 4], some parts of Africa [5, 6], and beyond $[7,8]$ that found FTC as the second common type of differentiated carcinomas of the thyroid gland. Historically, FTC has been linked to endemic iodine deficient regions of the World such as Ghana $[9,10]$. The expectation of the author was that FTC would be the commonest thyroid malignancy in Ghana, in accordance with findings from similar geographical settings $[11,12]$. However, this was not so. One potential explanation for the current finding is that the study was conducted in the southern part of the country where effects of iodine deficiency may have been masked by the consumption of iodine rich sea foods and thus do not give the true reflection of the picture across the country. This is more so because studies conducted in the northern parts of the Ghana more than 3 decades ago found higher incidence of iodine deficiency and increased prevalence of goiter in these areas especially along the Black Volta $[10,13]$.

Furthermore, the high $(35.0 \%)$ relative proportions of FTC among TCs in the current study differ from the $13-17 \%$ quoted in some literature [14], but in keeping with the $48.0 \%$ found in India, an iodine deficient country, by Parikh et al. [7] and $68.0 \%$ in South Africa by Mulaudzi et al. [11].

There was a gradual rise in the incidence of FTC during the period under review. The author has no specific explanation for this trend. This may however be a reflection of the general rise in the incidence of thyroid malignancies globally in recent years $[15,16]$.

In this study, FTC was commoner in females with the female to male ratio of $1.5: 1$. Follicular thyroid cancers like other thyroid malignancies for an unknown reason are found by studies to be female predominant [14, 17-19], a fact that is supported by this current study. The study found that FTC was commonly (in both females and male) diagnosed in a relatively older individual similar to the findings of previous studies $[3,4,9,19]$. 
TABLE 2: Histological subtypes and distant spread of FTCs at the time of histological diagnosis in females and males.

\begin{tabular}{|c|c|c|c|}
\hline & Female $(n / \%)$ & Male $(n / \%)$ & $P$ value \\
\hline \multicolumn{4}{|l|}{ Histological subtype of FTC } \\
\hline Conventional & $38(80.9)$ & $18(60.0)$ & 0.066 \\
\hline Hurthle cell & $5(10.6)$ & $8(26.7)$ & 0.116 \\
\hline Insular & $1(2.1)$ & $1(3.3)$ & 1.000 \\
\hline Minimally invasive & $1(2.1)$ & $2(6.7)$ & 0.557 \\
\hline Encapsulated & $1(2.1)$ & $0(0.0)$ & 1.000 \\
\hline Uncertain malignant potential & $1(2.1)$ & $1(3.3)$ & 1.000 \\
\hline Total & $47(100.0)$ & $30(100.0)$ & \\
\hline Distant spread & $9(19.1)$ & $7(23.3)$ & 0.775 \\
\hline Lymph node & $4(44.4)$ & $2(28.6)$ & 0.633 \\
\hline Bony involvements & $1(11.1)$ & $4(57.2)$ & 0.106 \\
\hline (i) Femur & $0(0.0)$ & $1(14.3)$ & 1.000 \\
\hline (ii) Clavicle & $0(0.0)$ & $1(14.3)$ & 1.000 \\
\hline (iii) Cervical vertebrae & $1(11.1)$ & $1(14.3)$ & 0.400 \\
\hline (iv) Rib & $0(0.0)$ & $1(14.3)$ & 0.000 \\
\hline Forehead (swelling) & $1(11.1)$ & $0(0.0)$ & 1.000 \\
\hline Neck muscle & $2(22.2)$ & $1(14.3)$ & 1.000 \\
\hline Dural mater & $1(11.1)$ & $0(0.0)$ & 1.000 \\
\hline Total & $9(100.0)$ & $7(100.0)$ & \\
\hline
\end{tabular}

The commonest clinical presentation of FTCs was an enlarged palpable anterior neck swelling (95.7\%), in keeping with studies across the globe $[3,4,9,23]$. In this study, $4.3 \%$ of the patients visited the health facilities with symptoms such as bone pain and fractures that are not primary symptoms of thyroid cancer. These were however found by examination and further investigations to result from metastatic follicular thyroid cancer. This supports studies that found that the primary presentation of FTC may be a metastatic disease $[24,25]$. The study found that patients (both females and males) with FTC commonly presented late to health facilities with disease, as found in other studies [9, 23]. FTC was common in total thyroidectomy specimens as found in other studies $[12,20,23,26]$.

Conventional FTC was commoner in the females ( $P$ value $=0.066)$ while the Hurthle variant was commoner in males $(P$ values $=0.116)[20]$. The current study found that $20.8 \%$ of the cases have spread beyond the thyroid gland at histologic diagnosis. In descending, these were cervical lymph node, bone, neck muscles, and dura mater. Nodal involvement was commoner in females $(P$ value $=0.633)$, while metastasis to bone was commoner in males $(P$-value $=0.106)$. Distant spread of FTCs at histologic diagnosis particularly to bones and brain has been reported in the literature. Our findings are thus in keeping with these previous studies [21, 22, 27]. The most likely explanation of the high proportions of cases with distant metastasis at histological diagnosis may be due to the fact that FTCs have affinity for blood vessels, a property that is considered as a key diagnostic feature.

The prognosis is general described as being favourable [27-29]. Although we have no data on the survival rate of the $35.0 \%$ people diagnosed with FTCs in this study, since there is no national cancer registry in Ghana, the author envisaged that the prognosis of the affected individuals will be favourable.

\section{Conclusion}

The study found a relative proportion of TFCs of $35.0 \%$, with a gradual rise in the trend over the period of study. Patients presented very late with huge thyroid gland enlargement. The female to male ratio was 1.5:1. Approximately, $20.8 \%$ had extraglandular spread at the time of histological diagnosis.

\section{Data Availability}

The data used to prepare this manuscript will be made available on demand.

\section{Disclosure}

Permission to conduct and publish this work was obtained from the Head of Department of Pathology (Professor RK Gyasi), School of Biomedical Sciences, College of Health Sciences, University of Ghana Legon.

\section{Conflicts of Interest}

The author declares that they have no conflicts of interest.

\section{Acknowledgments}

The author thanks the staff of the Department of Pathology whose work generated the data. He would also like to thank in a special way the Dean of the School of Medicine and Health Sciences, the University for Development Studies, Tamale, for reading through the final manuscript and offering his comments and correction. 


\section{References}

[1] M. Sobrinho Simões, S. L. Asa, T. G. Kroll et al., "Follicular carcinoma," in WHO Classification of Tumours. Pathology and Genetics. Tumours of Endocrine Organs, R. A. DeLellis, R. V. Lloyd, P. U. Heitz, and C. Eng, Eds., pp. 67-76, IARC Press, Lyon, France, 2004.

[2] U. Feldt-Rasmussen, "Iodine and cancer," Thyroid, vol. 11, no. 5, pp. 483-486, 2001.

[3] E. M. Der, S. E. Quayson, J. N. Clegg-Lamptey, E. K. Wiredu, R. K. D. Ephraim, and R. K. Gyasi, "Thyroid disorders in accra, ghana: a retrospective histopathological study at the Korle-Bu teaching hospital," Journal of Medical and Biomedical Science, vol. 21, pp. 1-7, 2013.

[4] J. C. B. Dakubo, S. B. Naaeder, Y. Tettey, and R. K. Gyasi, "Pathology and the surgical management of goitre in an endemic area initiating supplementary iodine nutrition," West African Journal of Medicine, vol. 32, no. 1, pp. 45-51, 2013.

[5] J. O. Thomas and J. O. Ogunbiyi, "Thyroid cancers in Ibadan Nigeria," East African Medical Journal, vol. 72, pp. 231-233, 1995.

[6] R. Asari, O. Koperek, C. Scheuba et al., "Follicular thyroid carcinoma in an iodine-replete endemic goiter region: A prospectively collected, retrospectively analyzed clinical trial," Annals of Surgery, vol. 249, no. 6, pp. 1023-1031, 2009.

[7] H. K. Parikh, R. S. Rao, S. S. Shrikhande, R. Havaldar, V. H. Deshmane, and D. M. Parikh, "Prognosticators of survival in differentiated thyroid carcinoma," Indian Journal of Otolaryngology and Head \& Neck Surgery, vol. 53, no. 1, pp. 6-10, 2001.

[8] R. Arora and A. Dias, "Iodine and thyroid cancer in Goa," The Online Journal of Health and Allied Sciences, vol. 4, no. 3, 2006.

[9] Ghana Health Service: Annual Report for the Year, Ghana Health Service, Accra, Ghana, 2007.

[10] E. Asibey-Berko, "Prevalence and Severity of Iodine Deficiency Disorders in Ghana," in Proceedings of the In Proceedings of the National Workshop on Iodine Deficiency Disorders in Ghana held in Accra, Ghana. Edited by: Asibey-Berko, E. Asibey-Berko and R. OrracaTetteh, Eds., pp. 15-23, University of Ghana, Ghana, 1995.

[11] T. V. Mulaudzi, P. K. Ramdial, T. E. Madiba, and R. A. Callaghan, "Thyroid carcinoma at King Edward VIII Hospital, Durban, South Africa," East African Medical Journal, vol. 78, no. 5, pp. 242-245, 2001.

[12] S. K. Eun, Y. K. Tae, M. K. Jung et al., "Completion thyroidectomy in patients with thyroid cancer who initially underwent unilateral operation," Clinical Endocrinology, vol. 61, no. 1, pp. 145-148, 2004.

[13] E. Asibey-Berko, A. G. B. Amoah, F. Addo, and E. Agyepong, "Endemic goitre and urinary iodine levels in rural communities in the Bolgatanga and Builsa districts of the upper east region of Ghana," East African Medical Journal, vol. 75, no. 9, pp. 501-503, 1998.

[14] A. Belfiore, G. L. La Rosa, G. A. La Porta et al., "Cancer risk in patients with cold thyroid nodules: Relevance of iodine intake, sex, age, and multinodularity," American Journal of Medicine, vol. 93, no. 4, pp. 363-369, 1992.

[15] American Cancer Society: Cancer Facts and Figures, American Cancer Society, Atlanta, GA, Georgia, 2014.

[16] B. A. Kilfoy, T. Zheng, T. R. Holford et al., "International patterns and trends in thyroid cancer incidence, 1973-2002," Cancer Causes \& Control, vol. 20, no. 5, pp. 525-531, 2009.
[17] A. Belfiore, D. Giuffrida, G. L. La Rosa et al., "High frequency of cancer in cold thyroid nodules occurring at young age," Acta Endocrinologica, vol. 121, no. 2, pp. 197-202, 1989.

[18] G. L. Clayman, T. D. Shellenberger, L. E. Ginsberg et al., "Approach and safety of comprehensive central compartment dissection in patients with recurrent papillary thyroid carcinoma," Head \& Neck, vol. 31, no. 9, pp. 1152-1163, 2009.

[19] C. S. Bal, A. K. Padhy, and A. Kumar, "Clinical features of differentiated thyroid carcinoma in children and adolescents from a sub-himalayan iodine-deficient endemic zone," Nuclear Medicine Communications, vol. 22, no. 8, pp. 881-887, 2001.

[20] C. De Crea, M. Raffaelli, L. Sessa et al., "Actual incidence and clinical behaviour of follicular thyroid carcinoma: An institutional experience," The Scientific World Journal, vol. 2014, Article ID 952095, 2014.

[21] Y. Mizukami, T. Michigishi, A. Nonomura et al., "Distant metastases in differentiated thyroid carcinomas: A clinical and pathologic study," Human Pathology, vol. 21, no. 3, pp. 283-290, 1990.

[22] S. N. Koppad and V. B. Kapoor, "Follicular thyroid carcinoma presenting as massive skull metastasis: A rare case report and literature review," Journal of Surgical Technique and Case Report, vol. 4, no. 2, pp. 112-114, 2012.

[23] S. Hölzer, C. Reiners, K. Mann et al., "Patterns of care for patients with primary differentiated carcinoma of the thyroid gland treated in Germany during 1996. U.S. and German Thyroid Cancer Group," Cancer, vol. 89, no. 1, pp. 192-201, 2000.

[24] C. S. Kumar, D. Shanmugam, R. Venkatapathy, and M. A. I. Munshi, "Metastatic follicular carcinoma of thyroid in maxilla," Dental Research Journal, vol. 10, pp. 817-819, 2013.

[25] F. D. Gilliland, W. C. Hunt, D. M. Morris, and C. R. Key, "Prognostic factors for thyroid carcinoma: A population-based study of 15,698 cases from the Surveillance, Epidemiology and End Results (SEER) program 1973-1991," Cancer, vol. 79, no. 3, pp. 564-573, 1997.

[26] "NCCN clinical practice guidelines in oncology: thyroid carcinoma version 1," National Comprehensive Cancer Network, 2016.

[27] N. Wada, K. Sugino, T. Mimura, M. Nagahama, W. Kitagawa, and H. Shibuya, "Treatment strategy of papillary thyroid carcinoma in children and adolescents: Clinical significance of the initial nodal manifestation," Annals of Surgical Oncology, vol. 16, pp. 3442-3449, 2009.

[28] M. A. Rosenbaum and C. R. McHenry, "Contemporary management of papillary carcinoma of the thyroid gland," Expert Review of Anticancer Therapy, vol. 9, no. 3, pp. 317-329, 2009.

[29] M. R. Pelizzo, I. Merante Boschin, A. Toniato et al., "Diagnosis, treatment, prognostic factors and long-term outcome in papillary thyroid carcinoma," Minerva Endocrinologica, vol. 33, no. 4, pp. 359-379, 2008. 


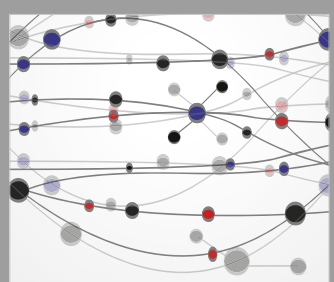

The Scientific World Journal
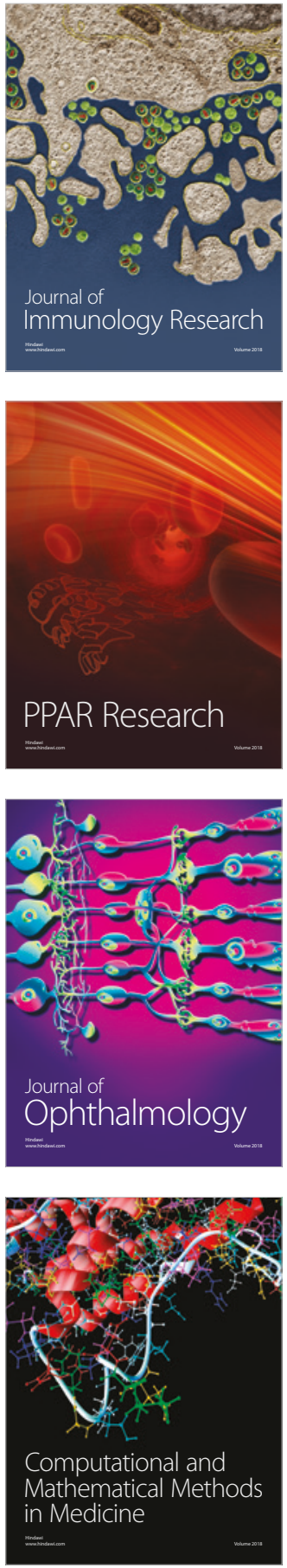

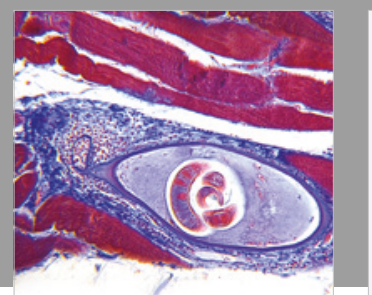

Gastroenterology Research and Practice

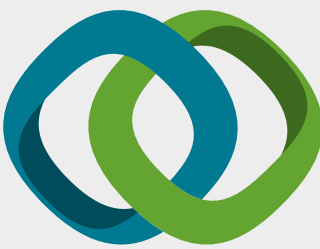

\section{Hindawi}

Submit your manuscripts at

www.hindawi.com
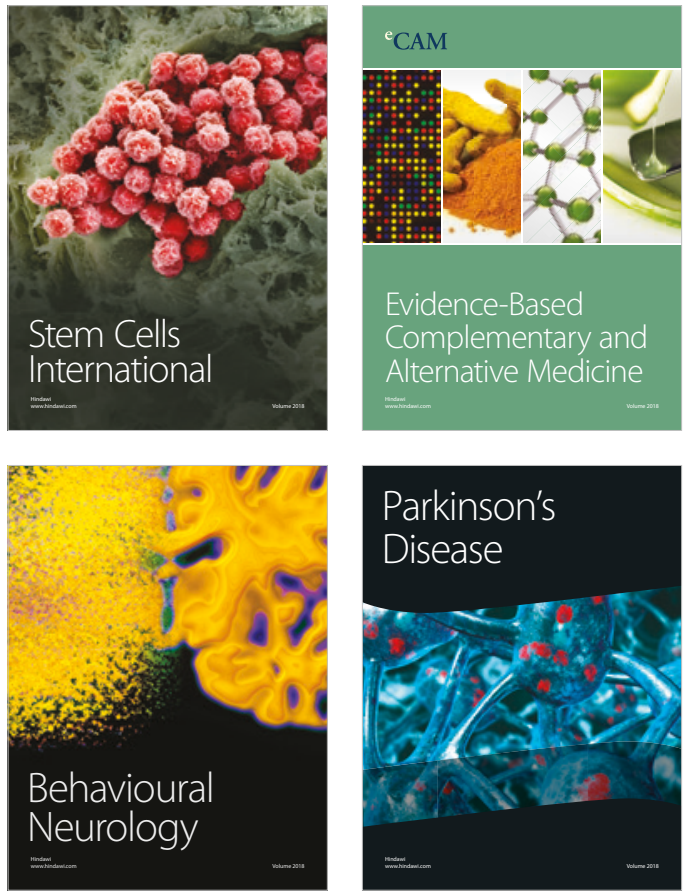

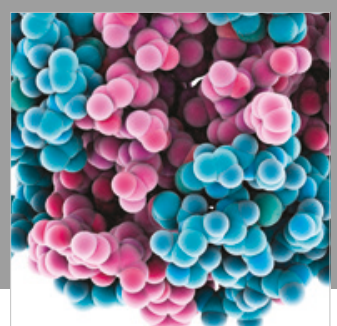

ournal of

Diabetes Research

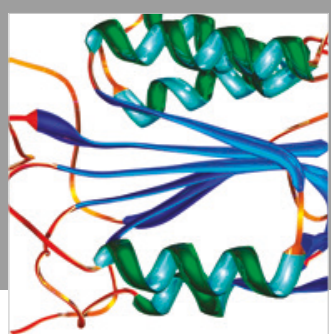

Disease Markers
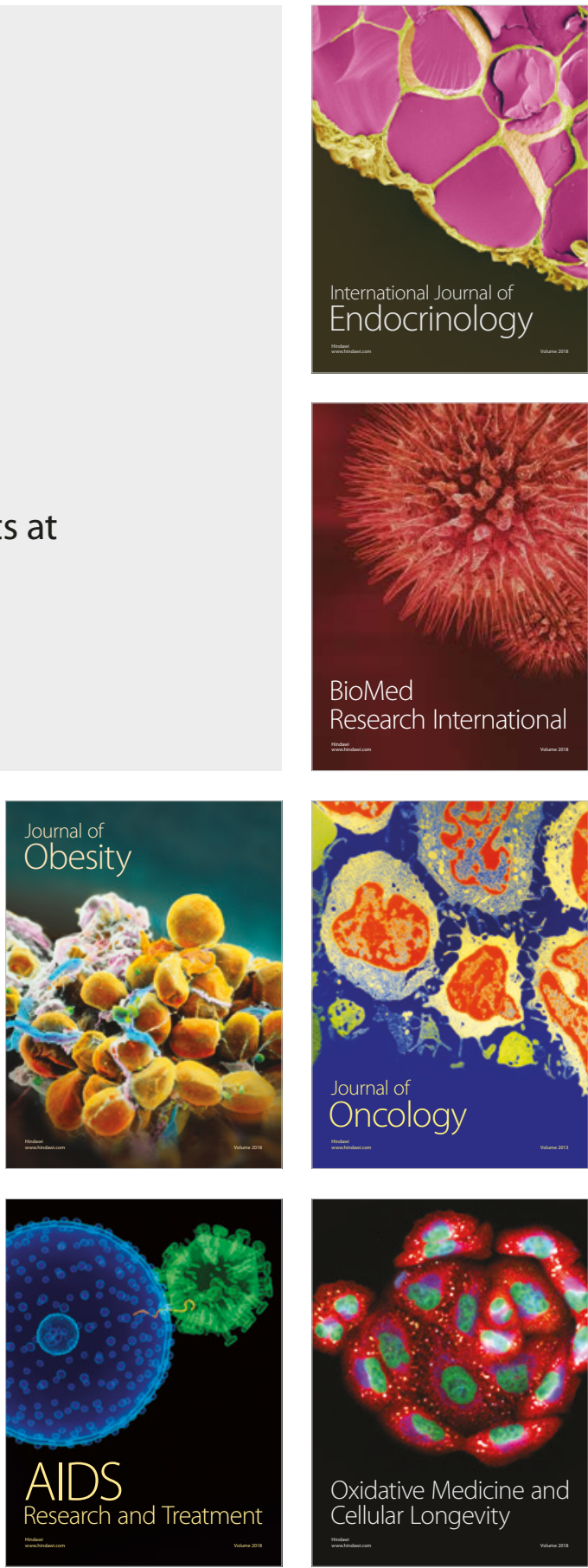